\title{
TRANSIÇÃO DEMOGRÁFICA, TRANSIÇÃO EPIDEMIOLÓGICA E ENVELHECIMENTO POPULACIONAL NO BRASIL
}

TRANSITION, EPIDEMIOLOGICAL TRANSITION AND POPULATION AGING IN BRAZIL

\author{
Anderson Silva Oliveira \\ Mestre em Geografia, Universidade Federal do Espírito Santo - UFES \\ andersongeo1980@hotmail.com
}

\begin{abstract}
RESUMO
Transição Demográfica, Transição Epidemiológica e Envelhecimento Populacional são processos interligados e produzem impactos significativos na sociedade. A mudança do comportamento demográfico, apresentando diferentes etapas, encontra-se atualmente na fase em que a fecundidade é reduzida a níveis mínimos, impactando na queda da participação do grupo das crianças na população, ao passo que a redução da mortalidade e a elevação da expectativa de vida, contribuem para o aumento do peso do grupo dos idosos. A medida que mais pessoas alcançam idades mais elevadas, ocorre a mudança do padrão de doenças que atingem a maior parte da população e que são as principais causas de mortes. Com mais idosos, as doenças típicas do envelhecimento assumem a liderança das enfermidades que mais acometem a população e que ocasionam a maior parte das mortes. Com a redução do grupo das crianças e a elevação sustentada do grupo dos idosos ocorre a intensificação do envelhecimento populacional, processo que provoca profundas transformações nos indivíduos, nas famílias e na sociedade como um todo e que exige uma total adaptação das políticas públicas para atender com qualidade ao cidadão com mais de 60 anos.
\end{abstract}

Palavras-chave: Envelhecimento populacional. Transição demográfica. Transição Epidemiológica.

\begin{abstract}
Demographic Transition, Epidemiological Transition and Population Aging are interconnected processes and produce significant impacts on society. The change in demographic behavior, presenting different stages, is currently at the stage where fertility is reduced to minimum levels, impacting on the fall of the participation of the group of the children in the population, while the reduction of mortality and the elevation of the expectation contribute to the increase of the weight of the elderly group. As more people reach higher ages, there is a change in the pattern of diseases that affect the majority of the population and are the main causes of death. With older people, the typical diseases of aging take the lead in the diseases that most affect the population and cause most of the deaths. With the reduction of the group of children and the sustained increase of the group of the elderly, there is an intensification of the aging population, a process that causes profound changes in individuals, families and society as a whole and which requires a total adaptation of public policies to attend to citizens over 60 years of age.
\end{abstract}

Keywords: Aging population. Demographic transition. Epidemiological transition.

\section{INTRODUÇÃO}

O Brasil está passando em termos demográficos por um período de grandes transformações que terão um peso importante para a situação econômica e social do país nas próximas décadas. Após sucessivos anos de crescimento populacional, o país vem registrando quedas acentuadas da

Recebido em: 11/05/2019

Aceito para publicação em: 07/10/2019 
natalidade, o que determina um ritmo cada vez menor de aumento do contingente populacional. A redução do número de nascimentos vem acompanhada pela queda da mortalidade, esses dois componentes juntos intensificam o processo de Envelhecimento Populacional. Com mais pessoas alcançando idades mais elevadas, uma série de mudanças são observadas como a Transição Epidemiológica, passando a mortalidade a predominar entre os mais velhos e as principais causas de morte passar a serem as doenças típicas do envelhecimento.

A mudança do comportamento da população (Transição Demográfica) reduz a participação do grupo das crianças na população e amplia o peso do grupo dos idosos. O país passa a ter um número expressivo de pessoas com 60 anos ou mais que demandam cuidados e atenção especiais para que possam manter a sua autonomia e bem-estar.

\section{TRANSIÇÃO DEMOGRÁFICA, TRANSIÇÃO EPIDEMIOLÓGICA E ENVELHECIMENTO POPULACIONAL}

O Envelhecimento Populacional tem estreita ligação com os processos de Transição Demográfica e de Transição Epidemiológica. Com a mudança do comportamento demográfico da população, com a variação dos níveis de natalidade e de mortalidade além dos movimentos migratórios, a população modifica a participação dos três grupos etários, tornando-se mais envelhecida ou jovem. O cenário atual observado no Brasil é de redução do grupo das crianças, em virtude da queda acentuada da fecundidade e do progressivo aumento do grupo dos idosos, com a elevação da expectativa de vida, fruto da melhoria das condições sociais e econômicas.

Segundo Castiglioni (2006), a Transição Demográfica consiste na passagem de uma situação de baixo crescimento populacional, resultado de elevados níveis de natalidade e de mortalidade, a uma outra fase marcada pelo baixo crescimento ou estabilização ou crescimento negativo, em que natalidade e mortalidade são baixas.

A Transição Demográfica contribui para o Envelhecimento Populacional e estes dois processos são associados à Transição Epidemiológica, que consiste na mudança do perfil de mortalidade, que passa de uma situação onde as principais causas de mortes são as doenças infecciosas e parasitárias, características de locais com baixos níveis de desenvolvimento econômico e social, para uma nova fase, em que as doenças típicas da velhice começam a ocupar uma posição cada vez mais intensa entre as enfermidades mais comuns (OLIVEIRA, 2015, p. 45).

Oliveira (2015), afirma ainda que a Transição Demográfica pode ser considerada o pano de fundo para as principais modificações e processos relacionados à população, dentre os quais está o Envelhecimento Populacional.

Com a mudança do comportamento demográfico observado ao longo do tempo, os níveis de fecundidade são reduzidos levando a queda dos nascimentos o que provoca uma nova distribuição dos três grupos etários ( 0 a 14 anos, 15 a 59 anos e 60 anos ou mais). A queda da fecundidade (desempenho reprodutivo efetivo de uma mulher) é acompanhada pela redução dos níveis de mortalidade que a princípio se concentra nas primeiras idades contribuindo para que um número maior de pessoas tenha condições de chegar ao grupo dos idosos. Há assim, uma participação de pessoas com mais de 60 anos que se amplia e uma redução do peso do grupo das crianças, ocasionando o envelhecimento da população.

Oliveira (2015) argumenta que com a estabilização do crescimento da população resultante da queda do número de nascimentos, ocorre o aumento relativo e sustentado da participação dos idosos na população total. O grupo etário jovem ( 0 a 14 anos) perde importância relativa, enquanto o grupo dos idosos (60 anos ou mais) ganha peso no total da população tornando-se mais envelhecida.

Com o envelhecimento, as principais doenças que acometem a população e que levam a morte se modificam, saímos de um quadro em que predominavam as doenças infecciosas e parasitárias que atingiam em sua maioria os mais jovens e passamos a um cenário em que as doenças crônicas e degenerativas assumem um peso maior. As doenças crônicas e degenerativas exigem uma alteração completa da rede de assistência à saúde. É uma realidade nova, são doenças que necessitam de ações preventivas e de acompanhamento constante. A rede de assistência médica do Brasil ainda 
muito pautada em ações curativas terá que adaptar-se para o atendimento de um contingente maior de idosos portadores de enfermidades que não são solucionadas com a aplicação de uma vacina ou com a ingestão de um medicamento.

As doenças típicas do envelhecimento já são as principais responsáveis pela maior parte das mortes observadas no Brasil e apresentam uma evolução ao longo dos tempos. De acordo com Castiglioni (2012), o grupo de doenças ligadas ao envelhecimento já era responsável por $68,4 \%$ das mortes no Brasil em 2010, sendo as doenças do aparelho circulatório as que mais matam no país.

A rede de assistência à saúde no Brasil ainda é muito voltada para o atendimento às crianças que durante muitas décadas representavam uma parcela considerável da população. O grupo dos idosos apresenta demandas de saúde e sociais totalmente diferentes dos outros segmentos da população e aumenta sua participação em um ritmo bastante intenso. Ampliamos o peso do grupo dos idosos em um espaço de tempo relativamente curto. Nos países desenvolvidos, primeiro houve à melhoria das condições de vida e só depois o envelhecimento da população. No Brasil, ocorre o envelhecimento sem o país ter apresentado grandes melhorias nas áreas de saúde e sociais. Assim, os desafios que se apresentam com a evolução do grupo dos idosos são imensos e precisam ser enfrentados visando colaborar para a manutenção do bem-estar da pessoa com 60 anos ou mais.

Acerca da qualidade de vida dos idosos nos próximos anos, Camarano afirma que:

\begin{abstract}
No futuro, os idosos terão melhores níveis de escolaridade e participação ativa na vida social e cultural. Tais características podem afetar positivamente as condições de saúde e bem-estar dos idosos, apontando para um cenário positivo, que dependerá, no entanto, de políticas públicas centradas na promoção da saúde desde as primeiras idades (CAMARANO, 2004, p. 86).
\end{abstract}

É preciso tornar a rede de assistência à saúde no Brasil mais eficiente o que pode colaborar para a redução da demanda pelos serviços e diminuir os custos.

Prata (1992) caracteriza o período de mudança do perfil de causas de mortes como sendo a passagem da mortalidade elevada, causada principalmente por doenças infecciosas para mortalidade baixa, na qual as doenças decorrentes do processo degenerativo do organismo e as causas externas passam a ocupar o topo do ranking de causas de mortalidade.

Nas últimas décadas, a expectativa de vida no Brasil vem apresentando ganhos expressivos, porém ainda podemos observar um grande percentual de mortes concentradas entre o grupo dos idosos que poderiam ser evitadas através do desenvolvimento de políticas preventivas ao longo da vida. $O$ incentivo de hábitos de vida saudáveis, por exemplo, pode colaborar para a redução de uma série de doenças que acometem os idosos.

Segundo Camarano (2002), o envelhecimento é algo em evidência mundial, significando um crescimento mais elevado da população idosa com relação aos demais grupos etários. Para Moreira (2001), envelhecimento populacional é entendido como o crescimento da população considerada idosa em uma dimensão tal que, de forma sustentada, amplia a sua participação relativa no total da população.

De acordo com Carvalho e Garcia (2003), o Envelhecimento Populacional é a mudança na estrutura etária, onde ocorre um aumento do peso relativo das pessoas com mais de 60 ou de 65 anos.

\title{
ENVELHECIMENTO POPULACIONAL NO BRASIL
}

Durante muito tempo o Brasil foi chamado de país do futuro, isso ocorria devido ao grupo etário das crianças (0-14 anos) ser bem expressivo frente ao grupo dos jovens e adultos e dos idosos. $O$ país ainda possui uma grande massa de crianças em sua população, no entanto, diante da queda do crescimento populacional do Brasil, o grupo de 0 a 14 anos vem apresentando sucessivas quedas.

De acordo Lebrão (2007), a imagem do Brasil como um país de jovens predominou por décadas, no entanto, de repente, percebemo-nos grisalhos.

Até os anos 70 , os elevados níveis de fecundidade acompanhados pela progressiva queda da mortalidade, contribuíram para o crescimento da população com considerável participação de 
crianças e jovens. O país já iniciava o processo de envelhecimento populacional, no entanto, o número de nascimentos e a entrada de crianças na população, reduzia o peso do grupo dos idosos.

O impacto da queda da mortalidade e da fecundidade no envelhecimento da população brasileira, somente começou a ser sentido no final do século passado e acerca do peso desses dois componentes na ampliação da população idosa no país. MOREIRA discorre que:

A queda da mortalidade brasileira que beneficiou proporcionalmente mais aos recém-nascidos, reduzindo-se mais fortemente a mortalidade infantil, combinada com níveis de fecundidade ainda por algum tempo relativamente elevados, fez com que o envelhecimento da população brasileira, mensurado pelo aumento da população idosa - acima de 65 anos - vis-à-vis a população jovem - menor de 15 anos - só se tornasse uma realidade social mais palpável já nas décadas finais do século XX (MOREIRA, 1998, p. 2).

Nas últimas décadas mudanças nos níveis de fecundidade e de mortalidade vem ocorrendo em ritmo e intensidade nunca vistos em épocas passadas.

O novo comportamento demográfico do Brasil com a redução dos nascimentos e queda do número de mortes provoca o envelhecimento progressivo da população. A figura 1 mostra a evolução da participação de idosos (60 anos ou mais) na população do Brasil ao longo dos anos. É possível observar uma clara tendência de elevação do peso do grupo etário dos idosos na população total do país.

Figura 1: Participação de idosos na população do Brasil 1970 a 2010

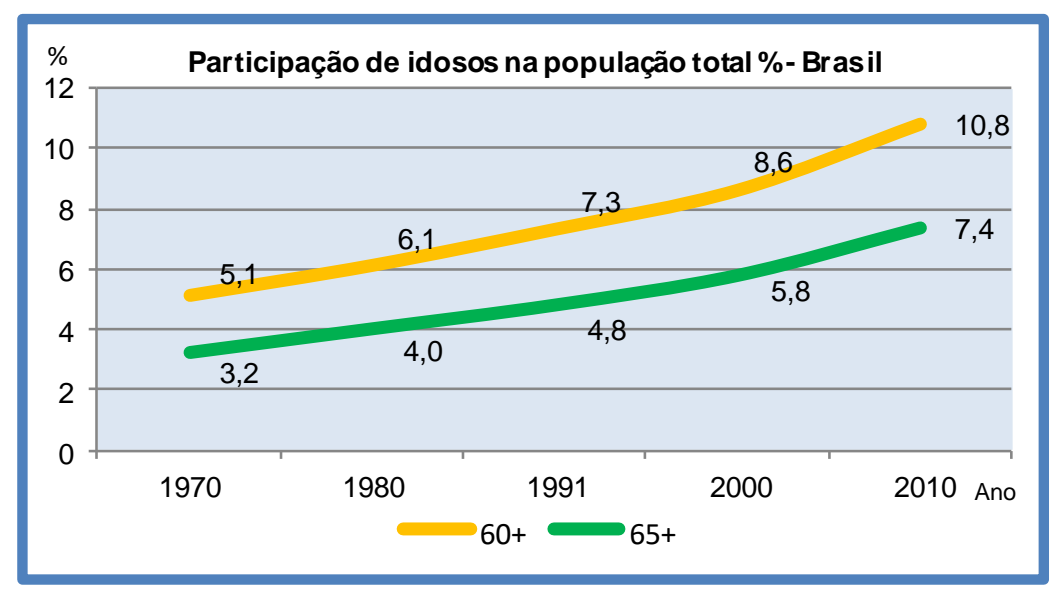

Fonte: Indicador calculado a partir de dados do Censo IBGE 2000 e 2010

Em 1970, a população idosa era reduzida em vista das condições de vida que ainda eram bem ruins e a expectativa de vida não era muito elevada. O Brasil encontrava-se na fase do processo de Transição Demográfica, em que a fecundidade era ainda elevada e a população do país crescia, sobretudo, o grupo etário jovem. A situação social do país era ruim e as famílias eram numerosas, reduzindo o peso do grupo dos idosos.

O aumento da participação de idosos na população do Brasil é fruto de transformações na distribuição etária sendo resultado, sobretudo da queda acentuada e constante da fecundidade. Segundo Instituto Brasileiro de Geografia e Estatística (IBGE) (2008), o país apresentará crescimento populacional positivo até 2039 e a partir desse ano o crescimento passará a ser negativo. Projeções do IBGE apontam ainda que em 2050, o grupo dos idosos ultrapassará o grupo das crianças, transformando o país em um dos países mais envelhecidos do mundo.

No envelhecimento populacional no Brasil é a fecundidade que tem um peso maior, sendo a queda dos nascimentos a principal responsável por uma nova distribuição dos grupos etários, reduzindo o peso do grupo das crianças e ampliando a participação do grupo dos idosos. Segundo Rios-Neto (2005), o atingimento de baixos níveis de fecundidade por muitos decênios ainda, será o fator 
principal para a intensificação do envelhecimento da população do país.

O número médio de filhos por mulher no país caiu mais da metade em 30 anos, sendo essa queda, reflexo de mudanças comportamentais das mulheres, do ingresso efetivo feminino no mercado de trabalho, da melhoria e do acesso a métodos contraceptivos, da intensificação do processo de urbanização e do aumento do nível de instrução, que avançou muito, especialmente nos anos 2000.

A redução acentuada da fecundidade pode ser considerada um sucesso de nossa sociedade. Para Asghar, (2008), a sociedade ofereceu muitas opções para as mulheres, que passaram a ter controle sobre a opção de ter filhos, a quantidade de filhos desejada e o momento da maternidade.

A redução da fecundidade tem um papel muito significativo sobre o envelhecimento, principalmente nos países em desenvolvimento como o Brasil. CARVALHO aponta o peso da queda da fecundidade no aumento da participação do grupo dos idosos no país.

$\mathrm{Na}$ realidade, a fecundidade é a grande definidora da estrutura etária, tendo a mortalidade apenas um papel secundário. Inclusive, quando esta declina, leva, normalmente, a um pequeno rejuvenescimento da população, pois, em sua trajetória de queda, são, geralmente, as taxas específicas de mortalidade (TEM) na infância aquelas que experimentam decremento proporcional maior. Como consequência, são salvas mais crianças do que adultos e idosos, o que tem um efeito sobre a distribuição etária semelhante ao de um aumento da fecundidade, isto é, tornar a população mais jovem (CARVALHO, 2004, p.6).

Embora ocorra em todo o país, o envelhecimento ocorre de modo heterogêneo em diferentes localidades. Observamos regiões mais envelhecidas, com proporções de idosos elevadas e áreas do país com participação bem tímida de idosos, apresentando grande número de crianças em suas populações. Quanto maior é o nível de desenvolvimento social e econômico, maior tende a ser a participação de idosos na população.

De acordo com Alonso (2010), o Envelhecimento Populacional no Brasil é heterogêneo e reflete as desigualdades regionais que são observadas no país.

Acerca da diversidade socioeconômica do Brasil Castiglioni (2012), afirma que essa é traduzida em modelos distintos de evolução quando analisamos os processos de Transição Demográfica, Transição Epidemiológica e do Envelhecimento Populacional entre as grandes regiões do país.

A ampliação do grupo dos idosos na população do Brasil ocorre de modo intenso e constante em uma trajetória sem volta. As próximas gerações serão compostas por um número menor de pessoas, com fecundidade extremamente baixa, os nascimentos não serão suficientes para frear o envelhecimento. O grupo dos jovens perderá mais espaço e o grupo dos idosos aumentará sua participação no total da população, o que fará emergir uma nova realidade demográfica, jamais vivenciada no país, com milhões de idosos, que demandarão novos serviços. KALACHE aponta alguns impactos do aumento de idosos na população do país:

O envelhecimento da população brasileira é um fato irreversível e que deverá se acentuar no futuro próximo imediato. O impacto desta nova ordem demográfica é imenso, sobretudo, quando se observa que os fatores associados ao subdesenvolvimento continuarão se manifestando por um tempo difícil de ser definido (KALACHE, 1987, p. 219).

Com a queda da mortalidade se concentrando nas idades mais avançadas, o país apresentará elevação do segmento dos mais idosos, composto por pessoas a partir dos 80 anos. O Brasil envelhecerá, reduzindo o grupo etário das crianças, aumentando o grupo dos idosos, com a elevação da expectativa de vida.

Nas próximas décadas, o declínio da mortalidade no Brasil, se concentrará, provavelmente, nas idades mais avançadas. Esse sim terá como efeito uma aceleração do processo de envelhecimento (CARVALHO, WONG, 2006, p. 8).

$\mathrm{Na}$ figura 2 podemos observar a tendência do progressivo processo de envelhecimento do Brasil a partir da análise do índice de envelhecimento (número de idosos observados para 100 crianças). Esse indicador ao longo dos anos demonstra que o número de idosos é cada vez maior em relação ao número de crianças. O índice de envelhecimento quase quadruplicou de 1970 até 2010. Estamos 
diante de um processo de redução da participação de crianças enquanto os idosos são cada vez mais numerosos na população total. O índice de envelhecimento (60 anos ou mais) é de 44,8 em 2010, significando que para cada 100 crianças nesse ano, existiam no país cerca de 44,8 idosos.

Figura 2: Índice de Envelhecimento da população do Brasil, 1970 a 2010

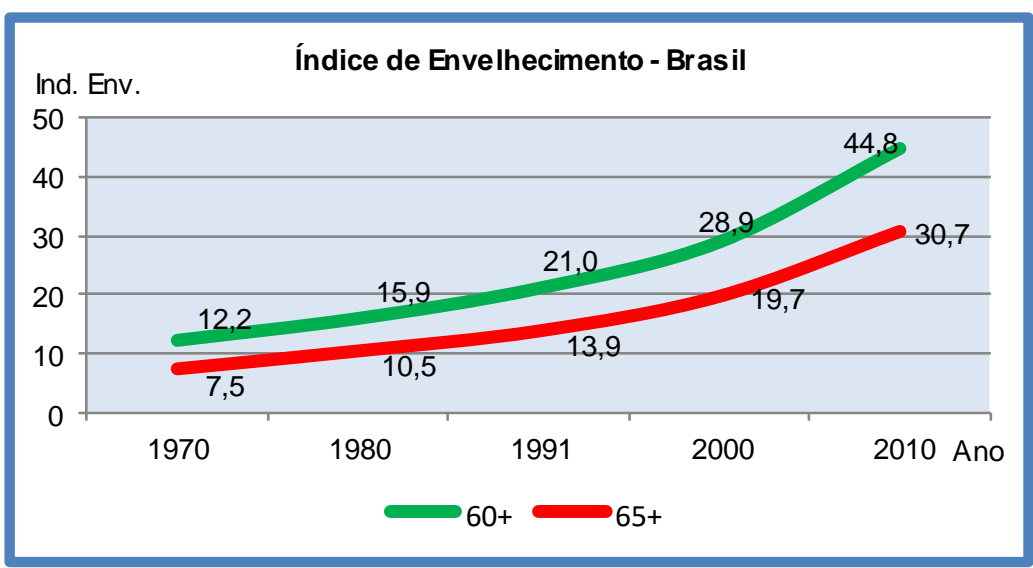

Fonte: Indicador calculado a partir de dados do Censo IBGE 2000 e 2010

A partir de 1970 o Brasil registra uma transformação da distribuição dos três grupos etários em sua população tal mudança afeta diretamente a economia do país.

Segundo Vasconcelos e Gomes (2012), em 1970 o Brasil deu início a uma verdadeira revolução demográfica com a redução da taxa de fecundidade, da natalidade e da mortalidade e com a elevação da expectativa de vida. Tais mudanças provocaram profundas transformações na estrutura etária do país, que tornaram o Brasil um país com uma distribuição etária mais amadurecida e com aumento constante do número de idosos e redução de crianças.

Tem início a partir dos anos 70 a queda progressiva do número de pessoas em idade inativa, (menores de 15 anos e maiores de 59 anos ou de 64 anos), que não participam diretamente População Economicamente Ativa (PEA) do país e que dependiam das pessoas em idade ativa.

A razão de dependência (número de pessoas em idade inativa - crianças e idosos, para cada grupo de 100 pessoas em idade ativa), está em queda. Essa redução é resultado da diminuição do número de crianças na população e ainda que haja um aumento do número de idosos, esse aumento ainda não é maior do que a redução do número de crianças.

A evolução da razão de dependência total no Brasil aparece representada na figura 3. Desde a década de 70 , a razão de dependência total está em queda constante, resultado de alterações na distribuição dos três grupos etários. Segundo economistas esse período de redução da razão de dependência representa uma excelente oportunidade para o Brasil desenvolver-se, pois o país tem um grande contingente de jovens em idade produtiva, diminuição de crianças e embora haja aumento do número de idosos, esse aumento ainda produz poucos impactos devido à quantidade de jovens que o país apresenta.

Segundo Camarano (2005), esse período favorável para o desenvolvimento do Brasil, com a queda sustentada da razão de dependência total (dependentes crianças e idosos) irá até por volta de 2020. A partir de 2020, a redução do número de jovens, começará a produzir impactos, passando a ter um menor percentual de jovens em idade ativa e um maior percentual de idosos.

A PEA do Brasil está em crescimento e se manterá assim até por volta de 2025, segundo (CARVALHO e WONG, 2006). A Transição da estrutura etária do Brasil oferece ao país uma janela de oportunidades, é o chamado "bônus demográfico", quando há um grande exército de mão de obra. O país não pode deixar essa fase passar, sem tomar medidas que contribuam para melhorar o seu nível de desenvolvimento social e econômico. Essa fase passará e deixará grandes impactos negativos e se não forem tomadas medidas agora, o país sofrerá muito em poucos anos. Vasconcelos e Gomes caracterizam o estágio do Brasil na Transição Demográfica:

O momento atual da transição demográfica proporciona ao país condições muito favoráveis. É o chamado bônus demográfico. Esse momento especial, que toda a 
sociedade experimentou, experimenta ou deverá experimentar, caracteriza-se pela redução da razão de dependência e sua relação com a proporção de população em idade ativa (15 a 59 anos). O impacto da redução do componente juvenil da razão de dependência ainda não foi superado pelo aumento do componente idoso (VASCONCELOS, GOMES, 2012, p. 548).

O Envelhecimento Populacional pode oferecer novas oportunidades para a sociedade caso haja uma preparação antecipada para enfrentar o processo. Asghar (2008) aponta que o envelhecimento apresenta-se, como um dos maiores desafios da modernidade e uma preparação com muita antecedência pode contribuir para um maior grau de coesão social entre as gerações. $O$ autor afirma ainda que a ampliação do grupo etário dos idosos pode se tornar um perigo se não formos capazes de levar em conta todos os desafios que esse fenômeno apresenta.

Figura 3: Razão de Dependência Total do Brasil, 1970 a 2010

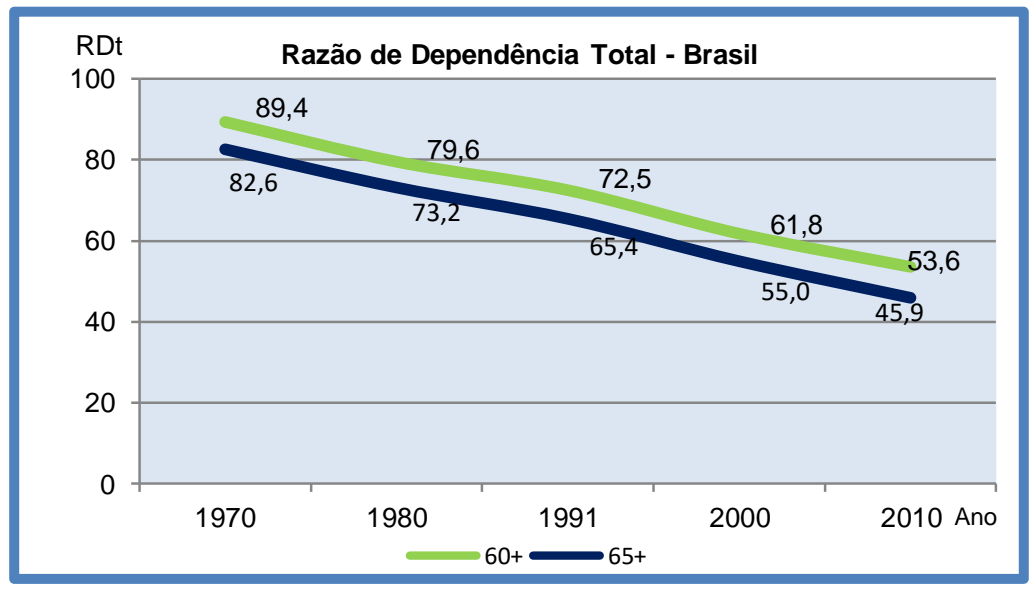

Fonte: Indicador calculado a partir de dados do Censo IBGE 2000 e 2010.

O Brasil tem um longo caminho a seguir visando melhorar o atendimento a população idosa. É preciso melhorar o sistema de ensino, qualificar o exército de trabalhadores, ampliar investimentos em saúde, qualidade de vida, programas de alimentação saudável, prática de esportes, pesquisas médicas e científicas, diversificação da economia, ampliar a cobertura da previdência social e torná-la mais eficiente. Estas medidas podem colaborar para preparar melhor o país para uma nova fase que está a caminho, onde teremos um número cada vez maior de idosos, dependentes de suas famílias, vinculados e por mais tempo à previdência, mais idosos em busca de atendimento de saúde, esporte e lazer e redução da mão de obra jovem.

A comparação das pirâmides etárias permite observarmos as principais mudanças na distribuição dos grupos etários no país. A figura 4 mostra a distribuição dos grupos etários por sexo no país em 1970.

Em 1970, a pirâmide etária do país refletia o comportamento demográfico da época em que predominam altos níveis de fecundidade. A pirâmide possui a forma típica de países pobres que apresentam baixos níveis de desenvolvimento econômico e social. A situação socioeconômica do país refletia no comportamento demográfico da população. As famílias eram bem numerosas, resultado do elevado número de nascimentos, desse modo, a pirâmide etária apresenta a base bem larga, grande participação de crianças e jovens na população total. A base e a parte mediana são alargadas e o ápice é bem estreito, devido ao reduzido número de idosos. A fecundidade alta impactava no processo de envelhecimento, que era pouco significativo, sendo a expectativa de vida não muito elevada.

Em 2010, as transformações na distribuição etária da população do Brasil, seguiram trajetória de redução das barras que representam as crianças e alargamento das barras referentes aos jovens, adultos e idosos. A figura 5 apresenta diferenças em relação à figura 4 e $o$ formato da pirâmide etária do país está em transição. A pirâmide do Brasil que em 1970, possuía o formato tradicional, típico de nações mais pobres, vem ganhando uma nova forma, que se aproxima dos países mais desenvolvidos. 
Figura 4: Pirâmide Etária do Brasil em 1970

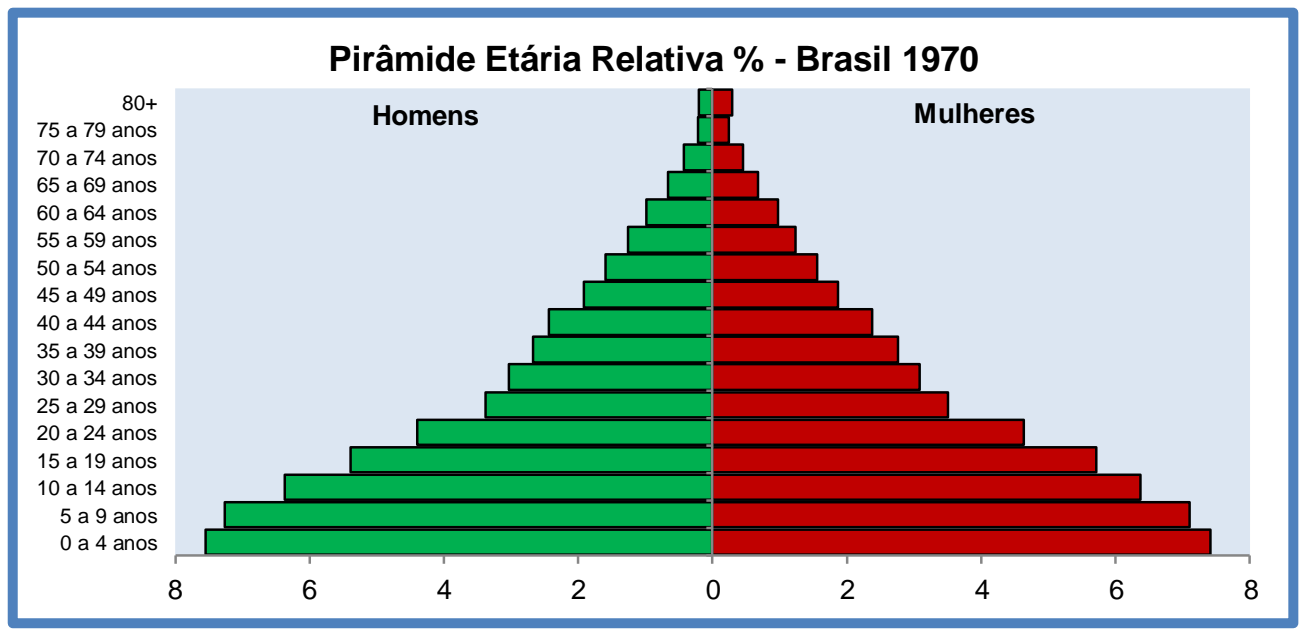

Fonte: Construída a partir de dados do Censo IBGE 1970

Figura 5: Pirâmide Etária do Brasil em 2010

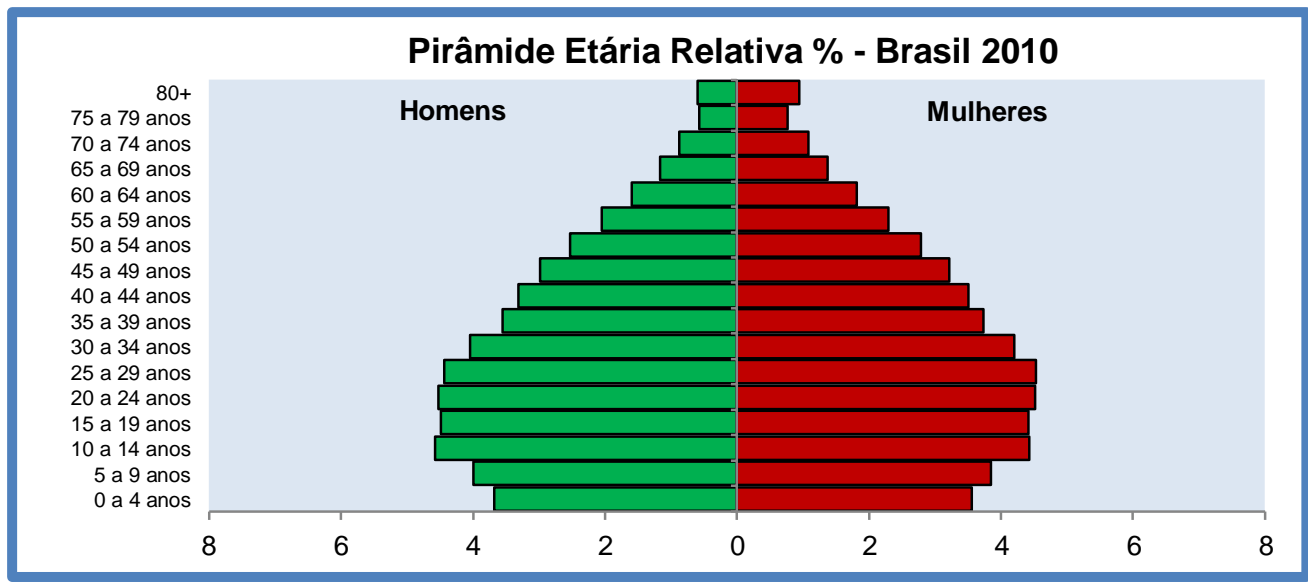

Fonte: Construída a partir de dados do Censo IBGE 2000

Houve a redução da base, reflexo da diminuição do número de nascimentos e o ingresso de menos crianças na população. Houve alargamento do meio da pirâmide, decorrente da elevação do grupo dos adultos e aumento do ápice devido à maior participação de idosos.

Em 2010, a pirâmide etária seguiu refletindo mudanças do comportamento demográfico do país com a melhoria das condições sociais e econômicas, além de mudanças culturais que impactaram de modo significativo na distribuição dos grupos de idade. Houve a redução da base da pirâmide, resultado da queda progressiva da fecundidade, com a diminuição de nascimentos e ampliação da participação de adultos e de idosos.

A queda da fecundidade provocou a redução da participação de crianças na população total ampliando a proporção de jovens e adultos. O declínio da mortalidade e a elevação da expectativa de vida fizeram com que a população ficasse mais envelhecida. Essas mudanças afetam a economia do país e exigem a aplicação de políticas públicas, voltadas para a geração de empregos, uma vez que, há uma grande massa de jovens e adultos e a melhoria do atendimento da parcela idosa da população que é maior e que envelhece em grande velocidade e que vive mais atingindo idades mais elevadas, ampliando a faixa dos mais idosos.

A pirâmide etária do Brasil começa a perder o formato tradicional (triangular), observado nos anos 70 e passa a apresentar uma gradual tendência de transição. O Brasil, que nos anos 70, encontrava-se em uma fase mais inicial da Transição Demográfica, está hoje em uma fase mais avançada, na qual a fecundidade em queda constante está próxima de atingir níveis extremamente baixos, comparados a

DOI: http://dx.doi.org/10.14393/Hygeia153248614 Hygeia 15 (31): 69 - 79, Junho/2019 página 76


países desenvolvidos e a elevar a expectativa de vida da população, ampliando de modo considerável o número de idosos.

O Brasil está a caminho da estabilização de sua população, o país ainda apresenta crescimento, mas é relativamente baixo, se compararmos com décadas passadas. A tendência populacional do Brasil é que a pirâmide etária atinja o formato típico das nações mais desenvolvidas. Em poucas décadas, o país terá ainda menos crianças e jovens e terá elevada população idosa o que fará aparecer novas demandas sociais. O Envelhecimento Populacional será notório e não haverá nada a ser feito para evitá-lo.

O envelhecimento da população brasileira ocorre em meio a condições de vida muito desfavoráveis para uma parcela ainda muito grande da população, Kalache (1987). O idoso ainda não recebe a atenção das autoridades e nem é alvo de políticas públicas intensas, como já ocorre em países desenvolvidos há muitas décadas. Com a ampliação do grupo dos idosos e redução do grupo das crianças essa realidade tende a mudar. "O envelhecimento no Brasil e na América Latina vem ocorrendo em um contexto marcado por uma alta incidência de pobreza, desigualdade social e um desenvolvimento desigual caracterizado pela falta de sintonia com o contingente da população idosa" (LYRA, 2008, p.13).

\section{CONSIDERAÇÕES FINAIS}

O Envelhecimento Populacional é um processo irreversível que vem acompanhado de profundas alterações que demandam do indivíduo que envelhece, de sua família, da sociedade de modo geral e das autoridades públicas adequações que precisam ser realizadas para que a fase da vida que começa aos 60 anos seja um período marcado pela autonomia, pela manutenção das funcionalidades e pelo amplo exercício da cidadania e do direito de ir e vir.

O Brasil envelhece a passos largos e atender o contingente de idosos que aumenta a cada ano é um imenso desafio. É uma realidade nova, nunca vivenciada pelo país, que deixa de ser uma nação de jovens e se transforma num país de idosos. São transformações que acompanham o aumento da participação de idosos na população que impactam sobretudo as áreas de saúde e sociais. O perfil de causas de mortes se modifica, passando a ter maior peso as doenças típicas do envelhecimento como doenças cardíacas, neoplasias etc., que precisam ser combatidas desde a infância, com o incentivo de hábitos de vida saudáveis. Doenças crônicas que as pessoas têm que conviver por longo período e degenerativas que vão debilitando a saúde do idoso dia a dia.

As mudanças no comportamento demográfico do país, iniciadas a partir dos anos 70 , contribuíram para a intensificação do envelhecimento da população do Brasil, que ocorre em vista a queda dos nascimentos e da mortalidade. A expectativa de vida se eleva e já está ocorrendo o envelhecimento dentro do grupo dos idosos, com destaque para o crescimento do número de idosos com 80 anos ou mais.

O Envelhecimento no Brasil ocorre em condições desfavoráveis, sobretudo para os mais pobres. O número de idosos aumenta principalmente devido à expansão das técnicas de saúde, medicamentos, hábitos de higiene sem que represente necessariamente melhoria das condições de vida.

O Envelhecimento da população exige amplo planejamento que envolve desde a pessoa que envelhece, à família, a sociedade como um todo e as autoridades públicas. São mudanças que se acompanhadas por ações efetivas melhoram a qualidade de vida, a autonomia do idoso, reduz a sobrecarga de trabalho que recai sobre a família, leva a sociedade a compreender e aceitar o idoso como ser social e permite sua participação nos eventos sociais e que diminui os gastos com medidas curativas de saúde.

\section{REFERÊNCIAS}

ALONSO, Fabio Roberto Bárbolo. Como envelhece uma população: uma análise demográfica dos componentes do crescimento populacional que conduziram ao acentuado e peculiar processo de envelhecimento da população do município de Santos. São Paulo. In: XVII Encontro Nacional de Estudos Populacionais, ABEP, Caxambú, Minas Gerais, 2010. 
ARAÚJO, José Duarte. Polarização Epidemiológica no Brasil. Informe epidemiológico do SUS, Brasília, ano 21, v. 4, p. 6-15, 1992.

CAMARANO, Ana Amélia. Envelhecimento da População Brasileira: Uma contribuição Demográfica. Texto para a discussão no 858, RJ: IPEA, 2002.

CAMARANO, Ana Amélia. Os novos idosos brasileiros. Muito além dos 60?. Rio de Janeiro: IPEA, 2004.

CAMARANO, Ana Amélia. Living longer: Are we getting older or younger for longer?.Vibrant: Virtual Brazilian Anthropology vol.13, no.1, Brasília Jan./June 2016. https://doi.org/10.1590/180943412016v13n1p155

CAMARANO, Ana Amélia (organizadora). Cuidados de longa duração para a população idosa: um risco social a ser seguido. Rio de Janeiro, IPEA, 2010.

CARVALHO, José Alberto Magno; GARCIA, Ricardo Alexandrino. O envelhecimento da população brasileira: um enfoque demográfico. Caderno de Saúde Pública, Rio de Janeiro, p. 725-733, maiojunho, 2003. https://doi.org/10.1590/S0102-311X2003000300005

CARVALHO, José Alberto Magno de. Crescimento populacional e estrutura demográfica no Brasil. Belo Horizonte. UFMG/Cedeplar, 2004. 18 p.

CARVALHO, José Alberto Magno de e WONG, Laura Rodriguez. O rápido processo de envelhecimento populacional do Brasil: sérios desafios para as políticas públicas. Revista Brasileira de estudos populacionais, São Paulo, v. 23, n. 1, p. 5-26, jan/jun, 2006. https://doi.org/10.1590/S0102$\underline{30982006000100002}$

CASTIGLIONI, Aurélia H. A revolução grisalha. Revista Fluminense de Geografia 4, Revista eletrônica da associação dos geógrafos brasileiros - AGB, ano 2 - jul/dez 2006.

CASTIGLIONI, Aurélia H. Inter-relações entre os processos de transição demográfica, envelhecimento populacional e transição epidemiológica no Brasil. In: V Congreso de ALAP Las transiciones em America Latina y el Caribe. Cambios demográficos, 2012.

GRUNDY, Emily. Population Ageing: Causes and Consequences. London School of Hygiene and Tropical Medicine, UK, 2006/2007. p. 87-92. HEALY, JUDITH. The benefits of an ageing population. Australian National University, discussion paper number 63, march, 2004. 62 p.

IBGE, Instituto Brasileiro de Geografia e Estatística. Censo 2010.

KALACHE, Alexandre; VERAS, Renato P.; RAMOS, Luiz Roberto. O envelhecimento da população mundial. Um desafio novo. Revista de Saúde Pública, São Paulo, v. 21, p. 200-210, 1987. https://doi.org/10.1590/S0034-89101987000300005

LEBRÃO, Maria Lúcia. O Envelhecimento no Brasil: Aspectos da Transição Demográfica e Epidemiológica. Revista Saúde Coletiva, São Paulo/SP, ano 4, vol. 17, Editorial Boliva, p. 135-140, 2007.

LYRA, Samira do Nascimento Mateus Nunes. O Envelhecimento da população brasileira e o aumento do uso de medicamentos: A atenção farmacêutica como política pública para 0 acompanhamento do uso de medicamentos. UFMG/FAFICH, Belo Horizonte/MG, 2008, 32 p.

MOREIRA, Morvan de M. O envelhecimento da população brasileira: intensidade, feminização e dependência. Universidade Federal de Pernambuco, 1998, p. 79-93.

MOREIRA, Morvan de M. Envelhecimento da população brasileira: aspectos gerais. In WONG, Laura L. Rodriguez (Org.). $O$ envelhecimento da população brasileira e o aumento da longevidade. Belo Horizonte: UFMG/Cedeplar: ABEP, 2001, p. 25-56.

OLIVEIRA, Anderson Silva. Envelhecimento Populacional e o surgimento de novas demandas de 
políticas públicas em Viana/ES. Dissertação de Mestrado, Programa de Pós Graduação em Geografia, Universidade Federal do Espírito Santo, 2015.

PRATA, Pedro Reginaldo. A Transição Epidemiológica no Brasil. Caderno de Saúde Pública, Rio de Janeiro, 8, p. 168-175, abr/jun, 1992. https://doi.org/10.1590/S0102-311X1992000200008

RIOS-NETO, Eduardo Luiz Gonçalves. Questões emergentes na análise demográfica: o caso brasileiro. Revista Brasileira de Estudos Populacionais, São Paulo, v. 22, p. 371-408, jul./dez, 2005.

WONG, Laura Rodrigues. 0 envelhecimento da população brasileira e o aumento da longevidade: subsídios para políticas orientadas ao bem-estar do idoso. Belo Horizonte, Cedeplar - UFMG/ABEP, 2001.

WONG, Laura Rodrigues. 0 rápido processo de envelhecimento populacional do Brasil: sérios desafios para as políticas públicas. Revista Brasileira de estudos populacionais, v. 23, n. 1, p.5-26, jan/jun de 2006. https://doi.org/10.1590/S0102-30982006000100002

ZAIDI, ASGHAR. Features and Challenges of Population Ageing: The European Perspective. European Center for social Welfare policy and research, Vienna, 2008. 